\title{
PENGARUH MODEL PEMBELAJARAN TREFFINGER TERHADAP HOTS PESERTA DIDIK DALAM MATA PELAJARAN IPS DI SMP NEGERI 1 GOMBONG
}

\author{
Nur Fitriani Sadiyah, Asep Ginanjar ${ }^{凶}$ \\ Prodi Pendidikan IPS, Fakultas Ilmu Sosial, Universitas Negeri Semarang, Indonesia.
}

\begin{tabular}{l}
\hline Info Artikel \\
\hline Sejarah Artikel: \\
Disubmit: Juli 2020 \\
Direvisi: Agustus 2020 \\
Diterima: September \\
2020 \\
\hline Keywords: \\
Inf;uence; Treffinger; \\
HOTS; Social Studies \\
Learning \\
\hline
\end{tabular}

\begin{abstract}
Abstrak
Lahirnya kurikulum 2013 menuntut peningkatan kemampuan berpikir peserta didik. Tujuan penelitian ini adalah untuk mengetahui pengaruh model pembelajaran Treffinger terhadap HOTS dalam Mata Pelajaran IPS di SMP Negeri 1 Gombong. Metode yang digunakan dalam penelitian ini yaitu kuantitatif. Hasil dari penelitian ini adalah (1) Pelaksanaan pembelajaran menggunakan model pembelajaran Treffinger di SMP N 1 Gombong terdiri dari tiga tahapan yaitu basic tools, practice with proces, dan working with the real problems Model pembelajaran (2) Treffinger berpengaruh dimana meningkatkan HOTS peserta didik pada pembelajaran IPS. Hal ini diketahui dari nilai sig. $=0,000<$ 0,05 dengan $t_{\text {hitung }}=-13,763$. HOTS dengan menggunakan model pembelajaran Treffinger berpengaruh lebih tinggi daripada dengan pembelajaran yang menggunakan model pembelajaran Konvensional. (3) Terdapat kendala dalam pembelajaran menggunakan model pembelajaran Treffinger yaitu perbedaan kemampuan setiap peserta didik dalam kesiapan menerima materi yang diberikan.
\end{abstract}

\begin{abstract}
The birth of the 2013 curriculum requires an increase in the thinking skills of students. The purpose of this study was to determine the effect of the Treffinger learning model on HOTS in social studies subjects at SMP Negeri 1 Gombong. The method used in this research is quantitative. The results of this study are (1) The implementation of learning using the Treffinger learning model at SMP $N 1$ Gombong consists of three stages, namely basic tools, practice with processes, and working with the real problems. The learning model (2) Treffinger has an effect which increases the HOTS of students at social studies learning. This is known from the value of sig. $=0.000<0.05$ with t_hitung $=-13.763$. HOTS using the Treffinger learning model has a higher effect than learning using the conventional learning model. (3) There are obstacles in learning using the Treffinger learning model, namely differences in the abilities of each student in readiness to receive the material given.
\end{abstract}

(C) 2020 Universitas Negeri Semarang

\footnotetext{
Alamat korespondensi:

E-ISSN 2685-4929

Gedung C1, Lantai 1, FIS Unnes

Kampus Sekaran, Gunungpati, Semarang, 50229

Email: asepginanjar@mail.unnes.ac.id
} 


\section{PENDAHULUAN}

Lahirnya kurikulum 2013 untuk menjawab tantangan dan pergeseran paradigma pembangunan abad ke-20 menuju abad 21 dimana menuntut dunia pendidikan agar mempersiapkan peserta didik menjadi lebih inofatif, kreatif dan afektif serta mampu berkontribusi pada kehidupan masyarakat, bernegara dan peradaban dunia serta persaingan yang lebih ketat salah satunya dengan cara peningkatan kemampuan berpikir peserta didik. Dalam Kurikulum 2013 Revisi Pemerntah mengharuskan pegintegrasian PPK, Literasi, 4C dan HOTS, salah satu aspek yang harus di integrasikan adalah HOTS Higher Order Thinking Skills.

Peningkatan kemampuan berpikir peserta didik sangat penting, taksonomi Bloom yang di revisi oleh Anderson dan Krathwohl dianggap sebagai dasar dari berpikir tingkat tinggi. Kategori dan proses kognitif yang termasuk dalam HOTS (Higher Order Thinking Skills) adalah C4, C5 dan C6 yaitu proses kognitif menganalisis, mengevaluasi dan mencipta (Anderson \& Kratwohl 2010). Analisis yang merupakan kemampuan berpikir dalam menspesifikasi asepek-aspek atau elemen dari sebuah konteks tertentu. Evaluasi merupakan kemampuan berpikir dalam mengambil keputusan berdasarkan fakta atau informasi dan mengkreasi merupakan kemampuan berpikir dalam membangun gagasan atau ide-ide.

Salah satu mata pelajaran yang ada di sekolah adalah IPS, IPS merupakan mata pelajaran yang memadukan konsep-konsep dasar dari berbagai ilmu sosial disusun melalui pendidikan dan psikologis serta kelayakan dan kemakmurannya bagi siswa dan kehidupannya (Samlawi \& Maftuh, 1999). Mata pelajaran Ilmu Pengetahuan Sosial dirancang untuk mengembangkan pengetahuan, pemahaman, ketrampilan dan kemampuan analisis terhadap kondisi sosial masyarakat dalam memasuki kehidupan masyarakat yang dinamis. Tujuan pembelajaran IPS adalah untuk mendidik dan memberi bekal kemampuan dasar kepada siswa untuk mengembangkan diri sesuai bakat dan minat, kemampuan dan lingkungannya (Solihatin dan Raharjo, 2009). Oleh karena tujuan dari pembelajaran IPS tersebut, mata pelajaran Ilmu Pengetahuan Sosial adalah salah satu mata pelajaran yang membutuhkan penerapan HOTS (Higher Order Thinking Skill) untuk meningkatkan kemampuan berpikir peserta didik.

Untuk mencapai tujuan tersebut pemilihan model pembelajaran yang tepat sangatlah penting. Untuk mngoptimalkan kemampuan HOTS (Higher Order Thingkng Skills) peserta didik penggunaan model pembelajaran Treffinger adalah alternative yang tepat. Karena model pembelajaran ini sangat optimal untuk meningkatkan kemampuan berfikir tingkat tinggi peserta didik. Model pembelajaran Treffinger merupakan salah satu model yang mengarah pada kemampuan berpikir kritis dan kreatif Model ini dikenalkan oleh Donald J. Treffinger pada tahun 1980.

Model Treffinger didasari dengan adanya perkembangan zaman yang terus berubah dengan cepat dan semakin kompleksnya permasalahan yang harus dihadapi. Karena itu, untuk mengatasi permasalahan tersebut diperlukan suatu cara agar dapat menyelesaikan suatu permasalahan dan menghasilkan solusi yang tepat (Huda, 2013). Seperti yang dikemukakan Treffinger (2003: 1) berikut ini: "Creative Problem Solving version 6.1 is a model to help you solve problems and manage change creatively. It gives you a set of easy to use tools to help translate your goals and dreams into reality". Model pembelajaran Treffinger adalah model yang membantu memecahkan masalah dan mengelola perubahan secara kreatif. Memberi satu set alat dengan mudah digunakan untuk membantu menerjemahkan tujuan dan impian menjadi kenyataan.

SMP Negeri 1 Gombong adalah salah satu SMP yang berada di Kabupaten Kebumen. SMP Negeri 1 Gombong yang strategis yaitu berdekatan di dekat pusat perekonomian Gombong dan bangunan bersejarah yang ada di Gombong yaitu Benteng Van Der Wick. masih banyak peserta didik yang menganggap bahwa mata pelajaran Ilmu Pengetahuan Sosial adalah mata pelajaran hafalan saja. Dan juga dalam pelaksanaan kegiatan pembelalajarannya masih di dominasi oleh keaktifan guru saja, dengan 
menganggap mata pelajaran IPS hanyalah mata pelajaran hafalan saja tanpa adanya pemahaman yang lebih mendalam, maka peserta didik akan memiliki pemahaman yang kurang atau masih rendah terhadap mata pelajaran IPS dan output yang dikeluarkanpun kurang maksimal dengan adanya bangunan sejarah yang ada di dekat SMP $\mathrm{N} 1$ Gombong maka model pembelajaran Treffinger dapat diterapkan dengan memasukan pembahasan mengenai lingkungan sekitar kedalam pembelajaran.

Rumusan masalah dalam penelitian ini adalah: 1) Bagaimana pelaksanaan Model Pembelajaran Treffinger dalam mata pelajaran Ilmu Pengetahuan Sosial di SMP Negeri 1 Gombong 2) Bagaimana pengaruh penerapan Model Pembelajaran Treffinger terhadap HOTS (Higher Order Thinking Skill) peserta didik dalam mata pelajaran Ilmu Pengetahuan Sosial di SMP Negeri 1 Gombong 3) Apa saja kendala penerapan Model Pembelajaran Treffinger dalam mata pelajaran Ilmu Pengetahuan Sosial di SMP Negeri 1 Gombong.

Peneltian ini bertujuan untuk: 1) Mengetahui pelaksanaan Model Pembelajaran Treffinger dalam mata pelajaran Ilmu Pengetahuan Sosial di SMP Negeri 1 Gombong 2) Menjelaskan pengaruh penerapan Model Pembelajran Treffinger terhadap HOTS (Higher Order Thinking Skill) peserta didik dalam mata pelajaran Ilmu Pengetahuan Sosial di SMP Negeri 1 Gombong 3) Mengidentifikasi kendala penerapan Model Pembelajaran Treffinger dalam mata pelajaran Ilmu Pengetahuan Sosial di SMP Negeri 1 Gombong. Hasil penelitian ini dapat menambah kemampuan HOTS peserta didik, menambah wawasan guru dan sekolah sebagai refleksi pembelajaran IPS di kelas, sebagai informasi dan dijadikan sebagai bahan pertimbangan bagi para pengambil kebijakan di bidang pendidikan

\section{METODE}

Penelitian ini menggunakan metode kuantitatif enggunakan Quasi Experimental Design dengan pola Nonequivalent Control Group Design.
Tabel 1. Ekperimen Quasi Nonequivalent Control Group Design

\begin{tabular}{|c|c|c|c|}
\hline Kelompok & $\begin{array}{c}\text { Pre- } \\
\text { Test }\end{array}$ & Treatment & $\begin{array}{c}\text { Post- } \\
\text { Test }\end{array}$ \\
\hline Kontrol & O1 & $\mathrm{X}$ & O2 \\
\hline Eksperimen & O3 & - & O4 \\
\hline
\end{tabular}

Sumber: (Sugiyono, 2016:79)

Populasi dalam penelitian ini adalah seluruh hasil belajar peserta didik kelas VIII SMP $\mathrm{N} 1$ Gombong yang terdiri dari lima kelas, dengan jumlah 159 peserta didik. Sempel dalam penelitian ini diperoleh dua kelas yaitu kelas VIII B (32 Peserta didik) sebagai kelas eksperimen dan kelas VIII C (32 Peserta didik) sebagai kelas kontrol, teknik pengambilan sampel dalam penelitian ini adalah menggunakan teknik purpose sampling. Variabel bebas dalam penelitian ini yaitu model pembelajaran Treffinger dan Variabel terikat yaitu HOTS.

Instrumen dalam penelitian ini terdiri dari pretest dan Postest. Teknik pengumpulan data menggunkan Observasi, Dokumentasi, Tes dan Wawancara. untuk mengetahui validitas realibilitas, dan analisis data dalam penelitian ini menggunakan bantuan software statistik IBM SPSS 22.0 for Windows. Sedangkan untuk mengetahui tingkat kesukaran dan daya beda soal menggunakan bantuan aplikasi AnBuso.

\section{HASIL DAN PEMBAHASAN}

\section{Penerapan Model pembelajaran Treffinger}

Model pembelajaran Treffinger yang dilakukan di kelas eskperimen VIII B SMP N 1 Gombong ada 3 tahapan yaitu basic tools, practice with process, dan working with real problems. Langkah pertama yaitu basic tools, pendidik menentukan tujuan, guru menginformasikan kompetensi yang harus dicapai, guru menyajikan suatu fenomena yang ada di sekitar lingkungan SMP N 1 Gombong berupa peninggalan sejarah yaitu benteng Van Der Wick, hasil rempahrempah Indonesia. Kemudian merumuskan masalah, guru memberikan kesempatan kepada peserta didik untuk mengidentifikasi masalah.

Tahap kedua yaitu Practice With Process guru membagikan lembar kerja pada setiap kelompok dan peserta didik berdiskusi sesuai 
kelompok masing. Bertujuan untuk memunculkan gagasan dari peserta didik yang dilakukan dengan cara mengemukakan pendapat mereka secara terbuka dan saling bertukar pendapat baik dalam kelopok masing-masing dan dengan kelompok lainnya.

Tahap ketiga yaitu Working With Real Problems. peserta didik diminta untuk menemukan pengaruh atau dampak materi yang dibahas dengan lingkungan sekitar, mengidentifikasinya dan guru mendorong peserta didik untuk memberikan solusi, setelah itu membangun penerimaan dimana guru mengecek solusi yang telah diperoleh peserta didik. Pada ahir pembelajaran guru memberikan intruksi untuk membuat artikel tentang peninggalan bangsa Belanda yang ada di Gombong beserta pengaruh atau dampaknya.

\section{Pengaruh Model Pembelajaran Treffinger terhadap HOTS Pesert Didik}

Didapat dari hasil tabel paired Samples Test, pada pair 1 dan 2 pretest kelas eksperimen dan kontrol dengan posttest eksperimen dan kontrol nilai sig. $=0,000<0,05$ maka $H_{0}$ ditolak dan $H_{1}$ diterima, artinya kesimpulannya bahwa terdapat perbedaan yang signifikan antara ratarata pretest dan posttest. Dengan kata lain model pembelajaran yang digunakan dalam kelas eksperimen (Treffinger) berpengaruh terhadap HOTS peserta didik.

Berdasarkan pada tabel Independent Samples Test diperoleh hasil homogenitas data), sig. $=0,042<0,05$. Artinya data tersebut bersifat heterogen atau ada perbedaan varians. signifikansi $0,000<0,05$. Jadi $H_{0}$ ditolak dan $H_{1}$ diterima, artinya terdapat perbedaan rata-rata kemampuan analisis peserta didik yang signifikan antara kelas eksperimen dan kelas kontrol. Karena terdapat perbedaan nilai ratarata yang signifikan, untuk melihat nilai rata-rata kemampuan analisis peserta didik yang paling tinggi dapat dilihat melalui rata-rata nilainya. Karena nilai rata-rata kelas eksperimen lebih tinggi yang dalam penelitian ini adalah kelas VIII B lebih tinggi dari nilai rarta-rata kelas kontrol atau kelas VIII , jadi dapat disimpulkan bahwa kemampuan analisis peserta didik kelas VIII B lebih tinggi dibanding kelas VIII C. Dimana nilai rata rata pretest kelas VIII B sebesar 63,709 dan kelas VIII C sebesar 57,775. Nilai posttest kelas VIII B sebesar 84,956 sedangkan kelas VIII C sebesar 76,303 dimana soal pretest dan posttest terdiri dari soal High Order Thinking Skills.

Peningkatan kemampuan analisis Hal ini dikarenakan pada kelas eksperimen pada tahap basic tools peserta didik diminta untuk mengungkapkan pengetahuannya secara tepat dan pendidik mengarahkan peserta didik untuk memahami konsep melalui fenomena-fenomena yang ada pada kehidupan sehari-hari yang berkaitan dengan materi pembelajaran secara langsung.

Peningkatan kemampuan mengevaluasi Hal ini terjadi karena pada pembelajaran menggunakan model pembelajaran Treffinger pada tahap working with real problems peserta didik diberkan suatu suatu masalah kemudian peserta didik diminta untuk menyelesaikan secara diskusi dengan kelompok masing-masing, kemudian peserta didik juga diminta untuk mengajukan suatu masalah dari berbagai pandangan lainnya. Sedangkan pada kelas kontrol peserta didik hanya diberikan soal-soal latihan tanpa memberikan suatu masalah atau suatu fenomena.

Peningkatan kemampuan mencipta $\mathrm{Hal}$ ini karena pada kelas eksperimen pada tahap practice with process dalam model pembelajaran Treffinger peserta didik diminta untuk memahami konsep secara utuh, sehingga pada saat diberikan suatu masalah peserta didik dapat mengembangkannya dengan rinci, dan pada tahap ini pula peserta didik diminta untuk menemukan masalah-masalah atau hal-hal yang baru atau hal lain yang ada di lingkungan seharihari yang berkaitan dengan konsep atau teori.

\section{Kendala Penerapan Model Pembelajaran Treffinger}

Kendala penerapan model pembelajaran Treffinger adalah kondisi peserta didik itu sendiri yang berbeda-beda, terkadang peserta didik yang membutuhkan waktu lebih lama untuk memahami suatu materi seringkali tertinggal, pada saat menyampaikan gagasan ada saja peserta didik yang kurang aktif dalam menemukan dan menyampaikan gagasan sehingga pemahaman terhadap materipun kurang, peserta didik harus dijelaskan lagi oleh 
guru mengenai materi agar lebih memahami, ini terlihat dalam hasil belajar dimana soal-soal yang diberikan terdiri dari soal-soal C4, C5 dan C6 masih ada peserta didik yang nilainya kurang maksimal.

Dalam proses pembelajaran menggunakan model Treffinger menuntut keaktifan peserta didik dan kemampuan untuk lebih berpikir kritis dalam memahami suatu materi, faktor kemampuan peserta didik yang berbeda-beda adalah faktor kendalanya, selain itu dalam berdiskusi dalam kelompok ada beberapa anak yang tidak maksimal dalam bekerja dengan kelompok mereka masing-masing. Untuk meminimalisi kendala atau hambatan yang muncul dalam kegiata pembelajaran berlangsung guru sebisa mungkin mengetahui kondisi dari kelompokkelompok belajar atau kelompok diskusi yang ada, sehingga dapat mengkofer apabila ada peserta didik yang kurang dapat mengikuti kegiatan pembelajaran yang menggunakan model pembelajaran Treffinger.

\section{SIMPULAN}

Berdasarkan hasil penelitian dan pembahasan, dapat ditarik kesimpulan sebagai berikut:

Pelaksanaan pembelajaran menggunakan model pembelajaran Treffinger di SMP N 1 Gombong terdiri dari tiga tahapan yaitu basic tools, practice with proces, dan working with the real problems dan dalam proses pembelajarannya memasukan pembahasan mengenai peninggalan sejarah yaitu Benteng Van Der Wick ke dalam materi.

Model pembelajaran Treffinger berpengaruh meningkatkan HOTS peserta didik pada pembelajaran IPS. Hal ini diketahui dari nilai sig. $=0,000<0,05$ dengan $t_{\text {hitung }}=-13,763$. Kemampuan berpikir tingkat tinggi peserta didik (HOTS) menggunakan model pembelajaran Treffinger berpengaruh lebih tinggi daripada dengan pembelajaran yang menggunakan model pembelajaran Konvensional. Terdapat kendala dalam pembelajaran menggunakan model pembelajaran Treffinger yaitu perbedaan kemampuan setiap peserta didik dalam kesiapan menerima materi yang diberikan.

\section{DAFTAR PUSTAKA}

Anderson \& Karthwohl. 2015. Kerangka Landasan Untuk Pembelajaran, Pengajaran dan Asesmen Revisi Taksonomi Bloom. Yogyakarta: Pustaka Pelajar

Huda, M. 2014. Model-Model Pengajaran dan Pembelajaran Isu-Isu Metodis dan Paradigma. Yogyakarta: Pustaka Pelajar.

Samlawi, Fakih \& Bunyamin Maftuh. (1999). Konsep Dasar IPS. Depdikbud: Dirjend. Dikti

Solihatin, Etin. 2008. Cooperative Learning Analisis Model Pembelajaran IPS. Jakarta: Bumi Aksara.

Sugiyono. 2016. Metode Penelitian Pendidikan: Pendekatan Kuantitatif, Kualitatif, dan $R \& D$. Bandung: Alfabeta.

Treffinger, Donald. J, Isaksen, S. G \& K. Brian Dorval. 2003. Problem Solving (CPS v6.1) A Contemporary Framework for Managing Change. New York: Creative Problem Solving Group, inc. 